\title{
7 Fs"

\section{Educação escolar quilombola no estado do Amapá: das intenções ao retrato da realidade}

Quilombola school education in the state of Amapá: from the intentions to the portrait of reality

Educación escolar quilombola en el estado de Amapá: de las intenciones al retrato de la realidade

\section{* Elivaldo Serrão Custódio}

Professor Pós-Doutor da Universidade Federal do Amapá (UNIFAP), Macapá, Amapá, Brasil. elivaldo.pa@hotmail.com

Recebido: 12 de janeiro de 2018

Aprovado: 11 de outubro de 2018

\section{RESUMO}

O presente artigo objetiva discutir sobre a educação escolar quilombola no estado do Amapá: das intenções ao retrato da realidade. Trata-se do resultado final de um dos capítulos de um estudo etnográfico de natureza qualitativa que adotou a pesquisa bibliográfica, a análise documental e a entrevista semiestruturada como forma de investigação. Os resultados apontam que a educação para as relações étnico-raciais, em especial a educação escolar quilombola no Amapá, está caminhando em passos muito lentos, pois apresenta normalmente ações pontuais e fragmentadas, sem articulação com a realidade local de cada comunidade quilombola, e muitas vezes, quando se apresenta é de maneira genérica e superficial. Os resultados apontam ainda escassez de profissionais qualificados e com falta de experiência na área quilombola. Além disso, a implementação da maioria das políticas educacionais para a efetivação da educação para as relações étnico-raciais tem ficado somente no papel, ou seja, no discurso e nos documentos oficiais, pois na prática, isso não tem se efetivado de fato e de direito.

Palavras-chave: Educação escolar; Quilombo; Amapá.

\section{ABSTRACT}

This article aims to discuss quilombola school education in the state of Amapá: from intentions to the portrait of reality. This is the final result of one of the chapters of an ethnographic study of a qualitative nature that adopted bibliographic research, documentary analysis and semi-structured interview as a form of investigation. The 


\section{OFEM \\ efituaráo

DOI: $10.5902 / 1984644430826$

Para Cavalleiro (2003, p. 98) "[...] o silêncio que atravessa os conflitos étnicos na sociedade é o mesmo que sustenta o preconceito e a discriminação no interior da escola". Sendo assim, não podemos só reconhecer e detectar a existência do racismo, mas combatê-lo no âmbito de toda a sociedade.

No Brasil, após a alteração da Lei $n^{\circ} 9.394 / 1996$ pela sanção da Lei $n^{\circ}$ 10.639/2003 e sua posterior regulamentação por meio do Conselho Nacional de Educação (CNE), Parecer CNE/CP n 03/2004 e da Resolução CNE/CP n 01/2004, foi estabelecida a obrigatoriedade do ensino de história e cultura africana e afrobrasileira nas escolas públicas e privadas da educação básica.

Assim, a partir da promulgação da Lei ㄲo 10.639/2003 e das Diretrizes Curriculares Nacionais (DCN) para a Educação das Relações Étnico-Raciais e para o Ensino de História e Cultura Afro-brasileira e Africana, foi estabelecido um marco legal, político e pedagógico de reconhecimento e valorização das influências africanas na formação da sociedade brasileira e do protagonismo da população afro-brasileira na formação social, política e econômica do país. Foram criadas, ainda, formas efetivas para o enfrentamento e a eliminação do racismo cultural, institucional e da discriminação nos contextos educacional e social.

De acordo com as DCN, temos a possibilidade de desmistificar a ideologia da igualdade racial, bem como viabilizar a valorização da pluralidade étnico-racial na educação brasileira. Sobre essa questão, Candau (2008, p. 51) nos recorda que toda vez que "a humanidade pretendeu promover a pureza cultural e étnica, as consequências foram trágicas: genocídio, holocausto, eliminação e negação do outro". Além desses fatores, a autora, também, destaca que as relações culturais não são idílicas, muito menos românticas; "[...] estão construídas na história e, portanto, estão atravessadas por questões de poder, por relações fortemente hierarquizadas, marcadas pelo preconceito e discriminação [...]" (CANDAU, 2008, p. 51).

Partindo da perspectiva que existe todo um marco legal que garante o direito e a permanência do estudo da história e da cultura africana e afro-brasileira no currículo das escolas brasileiras e que estas reflexões devem estar presentes no currículo escolar, principalmente em escolas localizadas nas comunidades quilombolas, objetivamos compreender até que ponto o currículo, os projetos, as 


\section{F Fes oultoará}

DOI: $10.5902 / 1984644430826$

ações e programas desenvolvidos na educação pública escolar quilombola no Amapá têm contribuído e/ou interferido no processo civilizador dos remanescentes de quilombo que se encontram nas escolas públicas quilombolas amapaenses.

A educação escolar tem possibilitado historicamente 0 acesso ao conhecimento produzido pela humanidade e ao mesmo tempo o desenvolvimento do indivíduo enquanto pessoa, através de valores e atitudes. Assim, é evidente e urgente uma atuação firme, democrática e incisiva do Estado na educação escolar quilombola, até porque hoje, já existe todo um movimento e estudos sobre educação escolar quilombola em nosso país.

Consideramos a presente pesquisa relevante para a educação escolar quilombola no Brasil e para a ciência porque contribui para a reflexão e discussão sobre cultura, história e memória no currículo escolar e a educação para as relações étnico-raciais em comunidades quilombolas. Dessa forma, o presente trabalho objetiva discutir, ainda, sobre a educação escolar quilombola no estado do Amapá: das intenções ao retrato da realidade. Trata-se do resultado final de um dos capítulos de um estudo etnográfico de natureza qualitativa que adotou a pesquisa bibliográfica, a análise documental e a entrevista semiestruturada no âmbito da Tese de Doutorado defendida em 2017.

A fim de alcançar os objetivos suscitados, estruturou-se este artigo em quatro seções. Na primeira seção, apresenta-se uma breve reflexão sobre educação escolar quilombola: algumas considerações sobre a política educacional para quilombos. $\mathrm{Na}$ segunda seção, discorre-se sobre a importância do projeto político pedagógico em escola quilombola: uma discussão necessária. Na seção subsequente, aborda-se sobre a educação escolar quilombola no estado do Amapá: das intenções ao retrato da realidade (2003-2017). Na quarta e última seção, apresentam-se algumas políticas de ações afirmativas desenvolvidas no Amapá para a educação das relações étnicoraciais e educação escolar quilombola (2008-2016), a partir das quais tecemos as considerações finais. 
DOI: $10.5902 / 1984644430826$

\section{Educação escolar quilombola: algumas considerações sobre a política educacional para quilombos}

A educação escolar quilombola é uma temática nova e contemporânea no que se refere às políticas públicas educacionais no país. De acordo com os dados oficiais, do Instituto Nacional de Estudos e Pesquisas Educacionais Anísio Teixeira (INEP), referentes aos dois últimos Censos Escolares da Educação Básica, em 2013, as escolas públicas em comunidades quilombolas eram de 2.235 unidades em atividade (BRASIL, 2013). No último Censo de 2014 publicado no Diário Oficial da União, no dia 09 de janeiro de 2015, o Brasil passou para 2.429 unidades escolares em atividade (BRASIL, 2014).

Embora os dados estatísticos oficiais demonstrem um aumento de 194 escolas localizadas em comunidades de remanescente de quilombo, esse número ainda é desproporcional ao quantitativo de comunidades existentes em todo território nacional. Em relação às questões como infraestrutura, formação de professores e currículo próprio, essa efetivação concreta, ainda, é um desafio para a educação brasileira.

Segundo as DCN's para educação escolar quilombola na educação básica:

A Educação Escolar Quilombola é desenvolvida em unidades educacionais inscritas em suas terras e cultura, requerendo pedagogia própria em respeito à especificidade étnico-cultural de cada comunidade e formação específica de seu quadro docente, observados os princípios constitucionais, a base nacional comum e os princípios que orientam a Educação Básica brasileira. $\mathrm{Na}$ estruturação e no funcionamento das escolas quilombolas, deve ser reconhecida e valorizada sua diversidade cultural (BRASIL, 2012, p. 21).

Lembramos que a educação quilombola realizada na escola precisa ser discutida e construída no diálogo com a comunidade como um todo, posto que de acordo com a Lei de Diretrizes e Base da Educação Nacional (LDBEN) de 1996, o conceito de Educação não se restringe apenas ao ensino escolar (BRASIL, 1996). Dentro dessa perspectiva, para que uma educação quilombola de qualidade faça sentido para os indivíduos dessas comunidades devem reconhecer, primeiramente, a existência desses quilombos, de sua realidade histórica e dos sujeitos que neles vivem. Para tanto, a educação escolar precisa ainda, compreender os processos 


\section{T Wism

DOI: $10.5902 / 1984644430826$

Quanto ao currículo da educação básica na educação escolar quilombola, de acordo com o que está exposto na Resolução no 08/2012, o documento traz algumas determinações como:

Art. 34 - O currículo da Educação Escolar Quilombola diz respeito aos modos de organização dos tempos e espaços escolares de suas atividades pedagógicas, das interações do ambiente educacional com a sociedade, das relações de poder presentes no fazer educativo e nas formas de conceber e construir conhecimentos escolares, constituindo parte importante dos processos sociopolíticos e culturais de construção de identidades. $\S 1^{\circ}$ Os currículos da Educação Básica na Educação Escolar Quilombola devem ser construídos a partir de valores e interesses das comunidades quilombolas em relação aos seus projetos de sociedade e de escola, definindo nos projetos político-pedagógicos (BRASIL, 2012, p. 13).

A Resolução $n^{\circ}$ 7, de 14 de dezembro de 2010 que fixa as DCN's, para o Ensino Fundamental de nove anos, ao tratar sobre a educação nas comunidades remanescentes de quilombos, salienta a importância do reconhecimento pelos sistemas de ensino do modo de vida das comunidades, ressaltando a importância da construção identitária dos discentes quilombolas, quando enfatiza a valorização das tradições, culturas e memórias compartilhadas (BRASIL, 2010). Ressaltamos que o currículo escolar quilombola também está reforçado pelo Plano Nacional da Educação para as Relações Étnico-raciais, pela Lei no 10.639/2003 e demais legislações.

Diante do exposto, percebemos que essas e tantas outras políticas educacionais e ações afirmativas para as comunidades quilombolas no Brasil vêm reforçar a ideia de quanto é importante uma educação de qualidade nas escolas quilombolas, bem como a efetivação de políticas educacionais que levem em consideração as histórias, as memórias, a identidade, os valores, os hábitos, as diferenças e características próprias dos quilombos.

\section{Projeto político pedagógico em escola quilombola: uma discussão necessária}

O Projeto Político Pedagógico (PPP) como parte integrante do processo de formação educacional discente não pode deixar de ser discutido e elaborado conforme a vivência local da escola, ou seja, o PPP da educação escolar quilombola não deve ser pensado de forma isolada e descontextualizada do cotidiano e vivência dessas comunidades. É necessário observar e levar em consideração todos os contextos: escola, família, comunidade e a sociedade em geral. 


\section{T HEM eltioarao}

DOI: $10.5902 / 1984644430826$

Verificamos que no processo educativo brasileiro, muitos professores e/ou profissionais da educação utilizam o termo "projeto político pedagógico" somente como uma ação pedagógica de fator político, considerando que essa proposta vise somente a formação do cidadão para determinada sociedade. Portanto, é preciso que a comunidade escolar seja esclarecida de que o planejamento do PPP da escola engloba vários aspectos como: o pedagógico - que é o eixo central das discussões , o administrativo, o jurídico e o comunitário.

Nesse sentido, é imprescindível que o currículo e o PPP da escola estejam em harmonia, principalmente quando se trata de questões como a diversidade cultural e religiosa, lembrando que esse ensino deve ser fixado a partir da realidade do aluno, observando a identidade particular de cada um.

O PPP quilombola deve agregar de maneira democrática os conhecimentos sobre a cultura, história, memória, ancestralidade e religiosidade africana e afrobrasileira dos educandos num diálogo constante na intenção de formar cidadãos capacitados, que possam interagir na vida socioeconômica, política e cultural do país.

Vale lembrar que o PPP deve ser avaliado, uma vez que há necessidade de saber se as metas que estão sendo traçadas, os objetivos que foram escritos realmente estão se concretizando. Fazendo isso, o PPP, se tornará um grande instrumento de trabalho indispensável, uma vez que define as políticas e os princípios filosóficos, otimiza os recursos pedagógicos, financeiros, e mobiliza os diferentes setores para a consecução dos objetivos.

\section{Educação escolar quilombola no estado do Amapá: das intenções ao retrato da realidade (2003-2017)}

Este tópico está fundamentado em relatos orais através de conversa informal e análise de documentos disponibilizados por Luciano Rodrigo de Oliveira, ${ }^{1}$ atual coordenador do Núcleo de Educação Étnico-Racial (NEER), órgão ligado a Coordenadoria de Educação Específica (CEESP) da Secretaria de Estado da Educação do Amapá (SEED).

\footnotetext{
${ }^{1}$ Diário de campo. Entrevista concedia no dia 22 de agosto de 2016 no NEER.
} 


\section{HEM

partir da criação da Lei $n^{\circ}$ 10.639/2003, provocando mudança estrutural na organização do Ministério da Educação (MEC) com a criação da Secretaria de Educação Continuada, Alfabetização, Diversidade e Inclusão (SECAD), esta, por sua vez, cria a coleção "Educação para todos" que é o primeiro grande instrumento público para empoderar os educadores sobre a diversidade quilombola do Brasil.

Quanto ao estado do Amapá, Luciano Rodrigo de Oliveira enfatiza que a educação quilombola foi uma estratégia educacional que surgiu junto com o estado, na década de 1990. Neste momento da história os quilombolas amapaenses passaram a ter mais importância do ponto de vista de contingência eleitoral. Para legitimar a lógica de criação de municípios era preciso ter eleitores em determinadas localizações no estado, sendo de suma importância para o êxito desse empreendimento. Dessa forma, a partir da década de 1990, começa a criação de escolas públicas no estado do Amapá.

Entretanto, nesse período, não se desenvolveu uma metodologia de ensino específico, devido a vários fatores, entre eles, o fato de que regiões do interior, ainda hoje, são pouco atraentes para a população que habita no estado ou por pessoas que vêm de outros estados pra cá. E como a maior parte das instituições quilombolas do Amapá estão nas áreas rurais, a contratação de professores torna-se difícil, outro fator preponderante. Para a implementação do ensino quilombola, as comunidades receberam equipamentos escolares, bem como uma pedagogia universal que era a preconizada na década de 1990, sendo o seu modelo maior a LDBEN, ou seja, uma educação generalista que ainda permanece até hoje nas escolas quilombolas amapaenses. E esse modelo de educação é muito mais forte nas zonas rurais do que nas localizadas na zona urbana.

Nos últimos anos, esse cenário vem mudando principalmente com a luta do Movimento Negro Estadual. Algumas pessoas que se destacaram como o professor Gil, da região do Quilombo do Cunani, que resolveu sair das atividades quilombolas ${ }^{2}$ e unir-se ao movimento negro, passando a solicitar às autoridades competentes o reconhecimento de escolas quilombolas amapaenses, bem como respostas mais

\footnotetext{
${ }^{2}$ Nessa região existia uma escola pública quilombola, mas que atualmente encontra-se fechada.
} 


\section{Ailthapão}

DOI: $10.5902 / 1984644430826$

concretas para aquelas pessoas que ali viviam e estudavam. Essas reivindicações fizeram com que várias pessoas que tinham uma formação mínima passassem a assumir gestão/direção e sala de aula dessas escolas quilombolas, assim como ocupar cargos públicos em Macapá. Isso por volta do ano 2000, onde o movimento social negro no estado começou a se fortalecer. Ressalta, Luciano Rodrigo de Oliveira, que muitas pessoas que fazem parte atualmente do movimento negro no Amapá são originárias dessas comunidades escolares, as quais realizam eventos e manifestações que permanecem até hoje.

A verdade é que do ano de 2000 pra cá, não é possível mais falarmos em uma educação quilombola de maneira uniforme e um processo educacional que no geral vai de $1^{\circ}$ ao $5^{\circ}$ ano do ensino fundamental da educação básica, mas de algumas escolas que oferecem também modalidade do 6ํㅜ ao 9‥ No Ensino Médio se torna ainda mais rarefeito em alguns casos porque no estado do Amapá, essa modalidade de ensino está concentrada mais na sede dos municípios. Essa deficiência tem dificultado a permanência dos alunos na escola, haja vista, muitos desses alunos quilombolas e não quilombolas, encontrarem obstáculos na continuidade de seus estudos, e precisam se deslocar para a sede dos municípios e/ou para outras regiões mais próximas.

Sobre a questão didático-pedagógica, seja da parte dos movimentos negros, seja de pessoas que assumiram cargos públicos e/ou de pessoas que organizaram movimentos sociais, iniciaram-se a partir de 2003 reivindicações para a atualização da política educacional voltadas para a população negra do estado do Amapá. Luciano Rodrigues de Oliveira afirma que essa atualização está sendo feita com muita lentidão, haja vista que as estruturas tradicionais do estado não modificaram. Mesmo com as mudanças que ocorreram na estrutura organizacional da SEED, muitas situações continuam no mesmo lugar literalmente. Além disso, as decisões educacionais são centralizadas e isso dificulta o atendimento como um todo da população do estado do Amapá.

Segundo Luciano Rodrigo de Oliveira, o Amapá não segue exemplos tão próximos como a educação desenvolvida no estado do Pará e de outros estados que descentralizaram as decisões educacionais. O Núcleo de Educação Étnico-racial 


\section{证

DOI: $10.5902 / 1984644430826$

ressalta que estão buscando nesse momento atualizar, do ponto de vista da legalidade educacional, as estruturas arcaicas que se mantêm desde as décadas de 1970-1990.

Em sua visão, Luciano Rodrigo de Oliveira afirma que o estado continua centralizado, porque a gestão democrática é algo que está sendo construído a passos lentos. Destaca que embora a Lei $n^{\circ} 10.639 / 2003$ já tenha mais de dez anos de existência, mais de $98 \%$ dos cargos de gestão, supervisão, coordenação entre outros são de indicação política partidária. Assim sendo, de alguma maneira todos esses elementos acabam atingindo tanto os gestores educacionais e políticos, quanto a população em geral.

Ressalta, o coordenador do NEER, que mesmo sem condições mínimas de qualificação, muitas pessoas têm assumido cargos públicos (direção de escolas, sala de aula, etc. $)^{3}$ o que de certa forma interfere consideravelmente na qualidade da educação escolar. E os órgãos competentes e fiscalizadores, se isentam da responsabilidade dentro das suas condições da categoria, o que fortalece a política partidária, que na maioria indica os cargos públicos na SEED e nos demais órgãos do governo.

Recorda Luciano Rodrigo de Oliveira que, em 2006, havia um movimento forte sobre como o estado precisava atender melhor a população negra amapaense dentre as lideranças que existem até hoje nos movimentos negros no Amapá. Na educação, cita, por exemplo, sua parceria com o Pedro Paulo de Carvalho (conhecido como Paulo Axé) que, no mesmo ano, articulou no Amapá a Rede Amazônia Negra e junto com o professor Silvaney Rubens Alves de Souza e com muitos outros articuladores colocaram o Amapá nesse circuito de grupos sociais que estavam concretamente reivindicando que a população negra amapaense tivesse uma educação de qualidade.

Lembra-nos, ainda, Luciano Rodrigo de Oliveira, que em 2007, foi chamado pra trabalhar na SEED na Divisão Técnico Pedagógica como auxiliar junto à equipe de Paulo Axé que trabalhava na Secretaria e que vinha desde então solicitando que

\footnotetext{
${ }^{3}$ A Resolução n 077/2014 do Conselho Estadual de Educação do Amapá, diz que preferencialmente a gestão deve ser ocupada por quilombolas. Além disso, conforme artigo $7^{\circ}$, inciso III, usa critério quanto à habilitação desse profissional, pois segundo esta resolução, o/a gestor/a tem que ter: licenciatura em pedagogia com pós-graduação na área de gestão ou administração escolar; ou graduação em programas especiais de formação pedagógica, com pós-graduação na área de gestão e/ou licenciatura em disciplinas específicas com no mínimo dois anos de docência.
} 


\section{Althrapão}

DOI: $10.5902 / 1984644430826$

as escolas atendessem a Lei $n^{\circ} 10.639 / 2003$. Entretanto, essas reivindicações não avançavam como deveriam, somente em 2008 é que foi criado o NEER do qual se tornou coordenador. Ressalta que a partir desse momento, puderam iniciar um trabalho mais voltado para a educação e relações étnico-raciais atendendo às escolas amapaenses, em especial às escolas quilombolas.

Na pergunta de como se encontravam os trabalhos do NEER, na atualidade, Luciano Rodrigo de Oliveira respondeu que, em geral, os gestores que passavam pelo NEER, recebiam uma biblioteca digital com mais de 80 livros, artigos e documentos diversos em pdf, cuja temática era a educação para as relações étnico-raiais, educação quilombola e indígena no estado do Amapá e fora do estado. De posse desse material, os gestores retornavam às escolas para aplicação e desenvolvimento de suas atividades. Enfatiza, o atual coordenador do NEER, que desde 2015 não tiveram a oportunidade de ir in loco nas escolas quilombolas pra ver de fato como anda o processo educacional, com exceção da Comunidade Quilombola do Curiaú, localizada no município de Macapá, próximo ao NEER. O entrevistado enfatiza que a SEED, nesse momento, não dispõe de transporte para locomoção desses técnicos até às comunidades quilombolas.

Luciano Rodrigo de Oliveira afirma que o obstáculo que mais atrapalha o processo educacional nas escolas quilombolas é o custo muito alto da educação no estado comparado a educação quilombola em outros estados brasileiros. Esse custo tem a ver com a distância das escolas, das secretarias de educação dos municípios, e ainda, com a falta de recursos para investir na educação. Destaca que, para se fazer uma ação com mais relevância, precisa contar com recurso federal, uma vez que o recurso estadual não é repassado com uma regularidade, além do mais, enquanto coordenadoria do NEER, desconhecem o orçamento estadual destinado a SEED, em especial o orçamento do NEER.

Cita Luciano Rodrigo de Oliveira, que paralelo a essas situações de dificuldades se encontram também dentro da SEED a falta de equipamentos adequados, a não disponibilização de telefone, a internet é precária, não tem transporte para fazer um evento e/ou planejar as atividades do ano letivo. $\mathrm{E}$ normalmente, os projetos apresentados no ano anterior têm que esperar a abertura 


\section{OFEM

DOI: $10.5902 / 1984644430826$

do orçamento do exercício seguinte, e nessa espera, ainda tem a dificuldade de conseguir autorização para execução e muitos projetos não chegam a sair do papel.

Mediante todos esses desafios, os trabalhos desenvolvidos são resultados da participação e parceria em projetos de outros órgãos governamentais e não governamentais. Observa-se que, não tem como fazer uma política que seja mais consistente se você não consegue ir até a escola, e mesmo quando se consegui ir, tem o problema da rotatividade de pessoas da gestão e/ou da sala de aula das escolas.

De acordo com o atual coordenador do NEER, essa questão da dificuldade de fixar profissionais nesses lugares mais distantes, também se dá pela falta de condições e infraestruturas adequadas, bem como a não valorização das pessoas que adquirem uma qualificação profissional, o que tem resultado em muitos retornos de professores para a capital do estado. A SEED, para remediar essas situações, contrata profissionais sem experiência e formação adequada para atuar nessas escolas de educação específica. Mesmo o NEER conseguindo dar suporte para esses profissionais, dificilmente, continuarão na educação quilombola, porque o contrato depende de uma articulação política partidária para ser renovado.

Em consequência dessas situações, entre outros fatores, o coordenador do NEER expressa que a educação quilombola, no Amapá, está muito fragilizada e mesmo sendo um órgão competente da pasta, não consegue materializar as políticas públicas para a população negra. E essa situação também tem refletido na vida social dessas comunidades, pois se percebe que a cada ano, o quantitativo de pessoas que vivem nessas comunidades quilombolas está diminuindo gradativamente. A qualidade de vida nessas regiões não gera mobilidade social, as pessoas mais jovens acabam saindo enfraquecendo a comunidade, e, por sua vez, a escola.

Em pergunta específica sobre $o$ atendimento e as ações que os professores desenvolvem nas escolas quilombolas, Luciano Rodrigo de Oliveira relata que, para atender os professores, utilizam a estratégia de divulgar seus trabalhos nos eventos que estão promovendo e/ou participando. Existe certa rotina nos trabalhos do NEER, quando um novo gestor assina contrato e/ou toma posse através de concurso público na SEED. Normalmente essa pessoa é convidada a conhecer as dependências e os 


\section{त

DOI: $10.5902 / 1984644430826$

trabalhos desenvolvidos pelo NEER, para que seja orientada quanto à educação escolar quilombola, que é originária do Conselho Nacional de Educação, do Ministério da Educação, do Conselho Estadual de Educação e também da própria SEED.

Luciano Rodrigo de Oliveira, conclui sua fala dizendo que essas questões que vem ocorrendo são muito sérias. E o NEER, enquanto órgão responsável pela implementação de políticas públicas voltadas para a população negra, tem suas limitações, porque o desenvolvimento de um trabalho de qualidade vai além de suas possibilidades e estão atrelados a uma dotação orçamentária, não tendo orçamento próprio e dependendo de autorização da SEED.

\section{Algumas políticas de ações afirmativas desenvolvidas no Amapá para a educação das relações étnico-raciais e educação escolar quilombola (2008-2016)}

Com base na análise de documentos oficiais e de acordo com informações sistematizadas de nosso Diário de Campo, destacamos algumas políticas de ações afirmativas que foram e/ou estão sendo desenvolvidos nos últimos nove anos pela SEED em parceria com outras Instituições, no Amapá. São encontros para discutir e buscar caminhos para a implementação de políticas públicas para as relações étnicoraciais, em especial para a educação escolar quilombola.

Vejamos as ações, cursos e projetos que vêm sendo desenvolvidos ao longo do período de 2008 a 2016: a) Programa Amapá Afro 4 na área da educação: Embora esse projeto referente ao eixo educacional esteja voltado para a efetivação da Lei no 10.639/2003 na educação pública amapaense, na prática, verificou-se que se apresenta de maneira muito genérica e superficial, não atendendo o objetivo principal que é a população negra, em especial, as localizadas nas comunidades quilombolas;

\footnotetext{
4 O Programa Amapá Afro criando em 2010 através da Lei Estadual de no 1.519/2010. Esse programa surgiu no cenário educacional amapaense de maneira interessante, anunciando ações que teriam como propósito a implementação da Lei no 10.639/2003, ideia que é reforçada pela Resolução no 075 de 26 de outubro de 2009/CEE-AP (CUSTÓDIO, 2014, p. 150). Entretanto, foi mais uma política de governo para atrair recursos federais. De acordo com o texto oficial, este Programa Amapá Afro tem por objetivo elaboração de políticas públicas de respeito à diversidade étnica, elevação da qualidade de vida da população negra, políticas de educação, saúde, cultura, trabalho, renda, esporte e lazer.
} 


\section{Tusm

DOI: $10.5902 / 1984644430826$

b) I Encontro Estadual de Educação Quilombola - realizado no período de 10 a 11 de novembro de 2011; c) II Encontro Estadual de Educação Quilombola e I Encontro de estudos Afroamapaenses - realizado no período de 06 a 08 de novembro de 2013; d) II Encontro Estadual Afroamapaense no Amapá - realizado no período de 07 e 08 de novembro de 2014; e) Encontro Estadual de Educação Quilombola - realizado no período de 04 a 06 de novembro de 2015; f) I Encontro Estadual de Gestores Quilombolas do Amapá - realizado no período de 25 a 26 de agosto de 2016; g) III Encontro Estadual de Educação Quilombola e Indígena - realizado no período de 25 a 27 de outubro de 2016.

De maneira geral, a SEED em parceria com outros órgãos, vem apresentando ações pontuais de entendimento e instrumentalização de políticas públicas voltadas para a implementação da Lei oㅜ 10.639/2003. Além disso, não há, ainda, uma proposta sistemática e satisfatória de atendimento educacional voltado para a educação escolar quilombola regional.

\section{Considerações finais}

A presente pesquisa verificou que a Lei o 10.639/2003 aponta para a necessidade de práticas educativas que orientem a formulação de ações e/ou projetos que visem à valorização da história e da cultura africana e afro-brasileira, em especial uma educação voltada para as relações étnico-raciais. Tanto a lei ㄲo 10.639/2003, bem como suas regulamentações (resoluções, pareceres, diretrizes curriculares, etc.) formam uma política educacional de Estado, que possibilita, pelo menos em tese, uma educação de direitos.

Quanto às políticas de educação para as relações étnico-raciais, em especial para a educação escolar quilombola no Amapá, estas estão caminhando em passos muito lento, pois são normalmente ações pontuais e fragmentadas, sem articulação com a realidade local de cada comunidade quilombola e que muitas vezes quando se apresentam são de maneira genérica e superficial.

Com base nos dados coletados, verificamos que embora o currículo escolar quilombola estadual amapaense, esteja reforçado no Plano Nacional da Educação 


\section{工 WEM

DOI: $10.5902 / 1984644430826$

para as Relações Étnico-raciais, na Lei n 10.639/2003 e demais legislações federais, assim como fundamentado no Plano Estadual de Educação do Amapá, na Lei Estadual no 1.196/2008, nas Resoluções estaduais nº 077/2014, 51/2012 e 025/2016 do CEE/AP, percebemos que a implementação de políticas educacionais para a efetivação da educação para as relações étnico-raciais e educação escolar quilombola, tem ficado somente no papel, ou seja, no discurso e nos documentos oficiais, pois na prática, isso não tem se efetivado de fato e de direito.

Segundo justificativa do representante do NEER/SEED as dificuldades de efetivação de políticas educacionais para a educação das relações étnico-raciais se dão por uma série de situações tais como: falta de conhecimento quanto a essas políticas disponíveis, infraestrutura inadequada, falta de recursos financeiros, falta de profissionais qualificados para atender esse segmento específico, falta de interesse, entre outros motivos.

Quanto ainda à educação escolar quilombola, percebemos que muita coisa ainda precisa ser feita, pois a estruturação da educação quilombola no estado do Amapá e a aplicabilidade da Lei $n^{\circ} 10.639 / 2003$ se deparam ainda com um sistema educacional complexo e deficitário já que a maioria das escolas quilombolas não têm um suporte e acompanhamento adequado. Igualmente, o acesso à continuidade a educação quilombola é muito difícil, pois muitos adolescentes, jovens e adultos, saem de suas comunidades porque não possuem acesso adequado à educação e/ou falta de oportunidade de continuar seus estudos. Além disso, a realidade da educação no campo é precária e muitas vezes somente na modalidade multisseriada. Ademais, há escassez de profissionais qualificados e com experiência com educação escolar quilombola.

Acreditamos que pensar em educação quilombola no Amapá implica, portanto, entender as relações existentes no dia-a-dia dos quilombolas e a relação deles com a terra, com o sagrado, com a cultura e com as diversas formas de organização. Entendemos que se as políticas públicas para essa população forem implantadas e avaliadas continuamente, podem trazer resultados satisfatórios na redução de desigualdades sociais, no combate à pobreza e na visibilidade dos principais problemas enfrentados por essa população. 


\section{F \\ 15SN: 1884-6449 \\ entuaḩa

DOI: $10.5902 / 1984644430826$

BRASIL. Conselho Estadual de Educação do Amapá. Resolução n 25/2016-CEE/AP de 02 de dezembro de 2015. Estabelece normas para criação e funcionamento das Instituições de Educação Escolar Quilombola, no âmbito da Educação Básica no Estado do Amapá e dá outras providências.

BRASIL. Conselho Estadual de Educação do Amapá. Resolução n 51/2012-CEE/AP de 26 de setembro de 2012. Estabelece normas complementares às diretrizes curriculares nacionais para a educação das relações étnico-raciais e para o ensino de história e cultura afro-brasileira, africana e indígena no currículo da educação básica e superior do sistema estadual de ensino do estado do Amapá e revoga a Resolução no 075/2009-CEE/AP. Macapá: 2012.

BRASIL. Ministério da Educação (MEC). Conselho Nacional de Educação. Parecer CNE/CP no 03/2004, de 10 de março de 2004. Disponível em:

<http://portal.mec.gov.br/dmdocuments/cnecp_003.pdf>. Acesso em: 10 jul. 2015.

BRASIL. Ministério da Educação (MEC). Instituto Nacional de Estudos e Pesquisas Educacionais Anísio Teixeira (INEP). Censo Escolar da Educação Básica 2013: resumo técnico. Disponível em:

<http://download.inep.gov.br/educacao_basica/censo_escolar/resumos_tecnicos/res umo_tecnico_censo_educacao_basica_2013.pdf>. Acesso em: 01 jun. 2016.

BRASIL. Ministério da Educação (MEC). Instituto Nacional de Estudos e Pesquisas Educacionais Anísio Teixeira (INEP). Censo Escolar da Educação Básica 2014. Disponível em:

<http://www.dataescolabrasil.inep.gov.br/dataEscolaBrasil/home.seam>. Acesso em: 01 jun. 2016.

BRASIL. Ministério da Educação. Câmara de Educação Básica do Conselho Nacional de Educação. Texto-referência para a elaboração das Diretrizes Curriculares Nacionais para a educação escolar quilombola. Brasília, DF: CNE, 2011.

BRASIL. Secretaria de Políticas de Promoção da Igualdade Racial (SEPPIR). Guia de Políticas Públicas para Comunidades Quilombolas. Programa Brasil Quilombola. Brasília-DF, 2013. Disponível em: <http://www.seppir.gov.br/portalantigo/arquivospdf/guia-pbq>. Acesso em: 25 jul. 2015.

CAVALLEIRO, Eliane dos Santos. Do silencio do lar ao silencio escolar: racismo, preconceito e descriminação na educação infantil. 2. ed. São Paulo: Contexto, 2003. $112 p$.

CANDAU, Vera Maria. Direitos humanos, educação e interculturalidade: as tensões entre igualdade e diferenças. In: Revista Brasileira de Educação, PUCRJ, v. 13, n 37, jan./abr., p. 45-56, PUCRJ, 2008. Disponível em: <http://www.scielo.br/pdf/rbedu/v13n37/05.pdf>. Acesso em: 08 jun. 2016. 
